\title{
PRINCÍPIO DO FATO CONSUMADO NO DIREITO ADMINISTRATIVO
}

\author{
MAURO RoBERTO GOMES DE MATTOS
}

\section{INTRÓITO}

No campo do direito civil, as nulidades de pleno direito são insanáveis, insuscetíveis de revalidação, ou no dizer de Pontes de Miranda, nos negócios jurídicos nulos "são insanáveis as suas invalidades e irratificáveis, tanto que confirmação deles a rigor não há, há afirmação nova, ex nunc, e de modo nenhum confirmação".'

Todavia, se, no campo do direito privado, o visceralmente nulo jamais pode ser sanado ou produzir efeitos válidos, na esfera do direito público a questão segue com menor rigorismo formal, em face da proeminência do interesse público.

Esta diferenciação é imperiosa, em face do desdobramento legal ser diferente nos distintos campos do direito, ressaltando as firmes considerações de Miguel Reale $^{2}$, sob o prisma da nulidade no direito administrativo, que deverá sempre ser distinguido em duas hipóteses: “ $a$ ) a de convalidação ou sanatória do ato nulo e anulável; $b$ ) a de perda pela Administração do benefício da declaração unilateral de nulidade (le bénefice de préalable).

Assim, focaremos a estabilidade das relações no direito público, mesmo que o ato administrativo tenha nascido de maneira irregular, que se convalida no transcurso do tempo, sempre com o intuito de preservar o interesse público e a segurança nas relações dos administrados com a administração pública.

Isto porque a desconstituição dos efeitos de atos administrativos já realizados há vários anos (mais de cinco), iria ferir a razoabilidade que cristalizou a realização dos atos.

No seu salutar Direito Administrativo Didático ${ }^{3}$, Sergio D' andrea já consignava que no conflito entre o interesse absoluto e a eliminação do ato jurídico viciado, o

1 Pontes de Miranda, apud Miguel Reale, Revogação e Anulação do Ato Administrativo, Forense, 1968 , p. 81.

2 Ob. cit. Ant., p. 82.

3 Direito Administrativo Didático, Rio de Janeiro, $3^{2}$ edição, Forense, 1985, pp.116/117.

R. Dir. Adm.,

Rio de Janeiro, 220: 195-208,

abr./jun. 2000 
interesse concreto da manutenção da segurança das relações jurídicas convalida os atos praticados.

Têm-se, portanto, que o tema sub oculis é intrigante, pois a Administração Pública possui em seu favor a consumação de seus atos pelo transcurso dos anos, especificamente em cinco anos, tendo em vista que o Decreto-Lei $n^{2} 20.910 / 32$, proclama a prescrição para os administrados que questionarem, após este prazo, atos administrativos.

O princípio que funciona em favor do ente público, em submissão a igualdade preconizada pelo caput do art. $5^{2}$ da CF., também se estende ao administrado, privilegiando o fato consumado.

E segundo De Plácido e Silva, o fato consumado é aquele cujos efeitos não podem mais ser modificados. ${ }^{4}$

Portanto, o fato consumado no direito administrativo possui a força de convalidar, ou até mesmo, sanear o ato nulo e anulável, como se demonstrará a seguir.

\section{O TRANSCURSO DO TEMPO COMO FATOR DE SEGURANÇA JURÍDICA}

A vida em sociedade, no mundo atual, revela a necessidade de se preservar a segurança jurídica das relações dos indivíduos com o Estado. E Hobbes, desde as priscas eras, já averbava que a segurança jurídica se conecta com a organização política na busca do preenchimento da finalidade pública.

No mesmo diapasão, Castillo Blanco ${ }^{5}$ averba:

"Así, finalidad del Estado y seguridad se identifican en las concepciones filosoficas y jurídicas apremiando a la organización política a mantener unas condiciones de certeza en la actuación estatal que permitan su normal desenvolvimiento".

A segurança jurídica funciona, assim, como resultado de um conjunto de técnicas normativas encaminhadas a garantir a própria consistência do sistema, que tem no fato consumado um dos elos de sustentação.

O desfazimento de atos que já produziram efeitos após vários anos, mesmo que sejam considerados viciados, se afigura como irrazoável.

Mais uma vez, abra-se parênteses para sublinhar a autorizada ótica de Miguel Reale que, em nome da ordem social, citou como exemplo a sanatória da nulidade do casamento contraído perante autoridade incompetente, se aquele vício não for

4 "Fato consumado - É o fato concluído. ou completo, cujos efeitos não podem mais ser alterados" (De Plácido e Silva, Vocabulário Jurídico, $17^{\text {a }}$ edição, Forense, atualizado por Nagib Slaibi Filho e Geraldo Magela Alves).

5 Frederico A. Castillo Blanco, La Protección de Confianza en el Derecho Administrativo, 1998, Marcial Pons, Madrid, p. 61. 
alegado dentro de dois anos da celebração, por qualquer interessado ou pelo Ministério Público: ${ }^{6}$ "da mesma o tempo transcorrido pode gerar situações de fato equiparáveis a situações jurídicas, não obstante a nulidade que originariamente os comprometia".

Figure-se, como outro exemplo, a situação levantada pela ilustre Maria Isabel Gallotti ${ }^{7}$, onde uma viúva que tenha recebido, durante anos, uma pensão com base em lei posteriormente inconstitucional, ou de um funcionário que tenha sido nomeado para o cargo criado por lei muito tempo depois julgada inconstitucional.

Como resolver esses casos em que uma norma jurídica foi pacificamente aplicada por um longo período e depois declarada ilegal?

De acordo com o bom senso, a primazia da realidade e o fato consumado, não é salutar que uma viúva devolva o valor correspondente a todos os anos de pensão recebida. Bem como, não se afigura como lícito, que se subtraia a pensão se ela integrou ao patrimônio jurídico e econômico da viúva após longos anos de pensionamento.

A idéia de se recorrer a sanatória ou convalidação dos atos nulos se coloca em termos menos rígidos na órbita do direito administrativo, não "por desamor ou menosprezo à lei, mas por ser impossível desconhecer o valor adquirido por certas situações de fato constituídas sem dolo, mas eivadas de infrações legais a seu tempo não percebidas ou decretadas". ${ }^{8}$

A fruição do tempo convalida o ato nulo, apagando novos efeitos ou interpretações contrárias as que geraram efeitos por certo lapso de tempo, gerando a estabilidade a determinada situação.

A estabilidade da relação jurídica projeta a segurança das relações travadas com o poder público.

Ela protege para o futuro os benefícios dela, como assevera Celso Antônio Bandeira de Mello: ${ }^{9}$

"A estabilidade - e este é o exemplo extremo - não tem outro significado, outro sentido, outra expressão lógica, senão proteger para o futuro os beneficiários dela. Afinal, estabilidade quer dizer permanência no tempo ! (...) Se uma disposição concessiva de estabilidade não for compreendida como a outorga de garantia de permanência no tempo, não tem como ser compreendida".

A sanatória ou convalidação do ato administrativo estável, considerado doente após vários anos de sua consumação, é destacado por Marcelo Caetano ${ }^{10}$ que, em laço de extrema felicidade, afirmou em alto e bom som:

6 Revogação e Anulamento do Ato Administrativo, Forense, 1968, p. 82.

7 RDA 170:29.

8 Miguel Reale, ob. cit. Ant., p. 83.

9 "Aplicação da Lei no Tempo em Direito Administrativo", in RDA 134/18.

10 Princípios Fundamentais de Direito Administrativo, Almedina, Coimbra, p. 187. 
"O ato doente cura-se com o decurso do tempo, e isso se dá porque o legislador pensa que a ilegalidade cometida não é tão grave que deva sobrepor-se ao interesse de pôr termo à insegurança dos direitos. Aos interessados, incluindo os representantes do interesse público, é facultado a anulação do ato; mas se não usarem oportunamente dessa faculdade, o interesse geral impõe que não fique indefinidamente a pensar sobre este ato a ameaça de anulação."

Em abono ao que foi dito, expressiva é a passagem do voto condutor do eminente Min. Cernicchiaro, no REsp. $\mathrm{n}^{\mathrm{e}}$ 136.204-RS: $:^{11}$

“ $\mathrm{Na}$ vida social, importa que não se eternize o estado de incerteza e de luta quanto aos direitos das pessoas; por isso, consolida-se a situação criada pelo ato nascido, embora com pecado original."

A necessidade de estabilizar as situações nas relações entre o administrado e a Administração está umbilicalmente ligado ao transcurso do tempo, que possui o escopo de imutabilizar a relação jurídica construída, mesmo que ela possua no seu nascimento o "pecado original".

Nenhuma dúvida existe que as relações anteriormente e totalmente consumadas são inatingíveis, quer pela mudança de interpretação, quer pela impossibilidade da nova norma jurídica retroagir para alcançar a situação já sepultada pelo tempo.

E nada mais belo e sensato do que trazer à lume as sábias palavras de Vicente Raó ${ }^{12}$ para quem:

"a inviolabilidade do passado é princípio que encontra fundamento na própria natureza do ser humano, pois, segundo as sábias palavras de Portalis, "o homem que não ocupa senão um ponto no tempo e no espaço, seria o mais infeliz dos seres, se não se pudesse julgar seguro nem sequer quanto à sua vida passada. Por essa parte de sua existência, já não carregou todo o peso de seu destino? O passado pode deixar dissabores, mas põe termo a todas as incertezas. Na ordem da natureza só o futuro é incerto e esta própria incerteza é suavizada pela esperança, a fiel companheira de nossa fraqueza. Seria agravar a triste condição da humanidade, querer mudar através do sistema da legislação, o sistema da natureza, procurando, para o tempo que já se foi, fazer reviver as nossas dores, sem nos restituir as nossas esperanças."

Dúvidas, portanto, não pairam que a estabilidade do tempo consuma a situação fática no direito administrativo, adquirindo o administrado a segurança de que a sua situação individual não sofrerá constantes revisões por parte da Administração.

11 STJ, REsp. n 136.204-RS (97.0041207-5), Rel. Min. Vicente Cernicchiaro, 6“ Turma, julgado em 21.10.97.

12 Vicente Raó, “O Direito e a Vida dos Direitos”, ed. RT, 3* ed., 1991, p. 323 


\section{III - A ESTABILIDADE DAS RELAÇÕES JURÍDICAS CONVALIDAM ATOS CONSTITUTIVOS DE DIREITO TRANSFERIDOS AOS SERVIDORES QUE SÃO ADQUIRENTES DE BOA FÉ.}

Um dos fatores que é prestigiado pela fruição do instituto da consumação do estado de fato, é a manutenção da estabilidade das relações jurídicas firmadas pelo poder público com os seus subordinados.

Sobre este posicionamento legal, tivemos a oportunidade de afirmar que:

"No campo do Direito Público a boa fé é o fator preponderante para manter a intangibilidade dos atos administrativos praticados em prol da coletividade, sendo irrevogável o ato que haja criado direito, mesmo que no futuro seja alterado ou revogado o comando legal instituidor do aludido direito." 13

Manoel de Oliveira Franco Sobrinho também observa que são irrevogáveis atos que já radiaram seus efeitos:

"O desfazimento, anulando relações, tornando o ato ineficaz, não apaga consequiências nem anula efeitos produzidos, pois os atos em começo de execução ou executados 'são considerados como irrevogáveis' tendo em conta condições materiais e o tempo de vigência." 14

Com o mesmo brilho, Francisco Campos, ao analisar a irretratabilidade dos atos administrativos que já produziram efeitos, ensina:

"a irretratabilidade dos atos administrativos, que decidem sobre a situação individual, é ainda, um imperativo de segurança jurídica." 15

Ainda sobre a estabilidade das relações jurídicas, Celso Antônio Bandeira de Mello, arremata:

"Finalmente, vale considerar que um dos interesses fundamentais do Direito é a estabilidade das relações constituídas. É a pacificação dos vínculos estabelecidos a fim de se preservar a ordem. Este objetivo importa muito mais no direito administrativo do que no direito privado. É que os atos administrativos têm repercussão mais ampla, alcançando inúmeros sujeitos, uns direta, e outros indiretamente, como observou Seabra Fagundes. Interferem com a ordem e estabilidade das relações sociais em escala muito maior. Daí que a possibilidade de convalidação de certas situações — noção antagônica à de nulidade em seu

13 Mauro Roberto Gomes de Mattos, "Compêndio de Direito Administrativo - Servidor Público", ed. Forense, 1998, p. 373

14 "Atos Administrativos", ed. Saraiva, 1980, p. 174

15 "Direito Administrativo", Forense, vol. II, p. 7 
sentido corrente - tem especial relevo no direito administrativo. Não obrigam com o princípio da legalidade, antes atendem-lhe o espírito, as soluções que se inspirem na tranqüilização das relações que não comprometem insuprivelmente o interesse público, conquanto tenham sido produzidas de maneira inválida. É que a convalidação é uma forma de recomposição da legalidade ferida. Portanto, não é repugnante ao direito administrativo a hipótese de convalescimento dos atos inválidos." 16

Da mesma forma, Lúcia Valle Figueiredo ensina:

"Destarte, por força de erro administrativo, podem surgir situações consumadas, direitos adquiridos de boa fé. Diante das situações fáticas constituídas, rever tais promoções (hipótese consideradas) seria atritar com princípios maiores do ordenamento jurídico, sobretudo com a segurança jurídica, princípio maior de todos, sobre o princípio, como diz Norberto Bobio". ${ }^{17}$

E José Frederico Marques, se filiando a corrente citada, adverte:

"limite imposto à revogabilidade está no respeito aos direitos subjetivos por perfeitos criados pelo ato administrativo." 18

No mesmo contexto, a Jurisprudência constitui elemento sólido que preserva a boa fé do administrado, e convalida o ato já praticado sob este manto:

"O Poder Público atentaria contra a boa fé dos destinatários da administração se, com base em suposta irregularidade por ela tanto tempo tolerada, pretendesse a supressão do ato." 19

Como se vê, tanto a moderna doutrina, como a jurisprudência dominante, orientam, de modo firme e consensual, no sentido de que, em face do caso concreto, pode acontecer que situações resultantes de ato administrativo, embora nascidos "irregularmente" pela ótica da Administração, devem ser convalidados, não só pela aquisição de direitos dos servidores públicos (art. 5, XXXVI da C.F.), como também pelo fato da aquisição de direitos ter sido consumado pelo manto da boa fé.

Destarte, não se admite na doutrina e na jurisprudência que ocorra anulação ou revogação de ato administrativo que já tenha gerado direitos aos beneficiários de boa fé, acarretando instabilidade jurídica para os mesmos, imperando o princípio

16 “Curso de Direito Administrativo", 9" ed., Malheiros, pp 297/298 ("Curso de Direito Administrativo", $9^{a}$ ed., Malheiros, pp 297/298)

17 “Curso de Direito Administrativo", 1994, p. 151

18 RDA 39:18

19 Ap em Ms $n^{2}$ 90.04.06891-0-RS, in RTRF-4, $n^{2}$ 6, p. 269. 
clássico de que "a parte útil não deve ser afetada pela inútil." (utile per inutile sem vitiatur).

O STF, através da autorizada visão do Ministro Lafayette de Andrada, firmou o entendimento que o tempo é o verdadeiro verdugo da retratabilidade do ato administrativo:

“A verdade, porém, é, que se criou uma situação de fato, que o tempo já consolidou. Em casos semelhantes, a orientação do Supremo Tribunal ter sido no sentido de atender a tais situações cuja excepcionalidade aconselha encarar o problema mais sob o aspecto da finalidade social das leis do que de uma severa interpretação literal dos textos." 20

E o Ministro Prado Kely, também do STF, assim redigiu a ementa de outro julgado:

"Ocorrência, na espécie, de circunstâncias excepcionais que aconselham a inalterabilidade da situação de fato e de direito constituída pela concessão da liminar."21

Ademais, já escreveu Miguel Reale:

"Assim sendo, se a decretação de nulidade é feita tardiamente, quando da inércia da Administração já permitiu se constituíssem situações de fato revestidas de forte aparência de legalidade, a ponto de fazer gerar nos espíritos a convicção de sua legitimidade, seria deveras absurdo que, a pretexto da eminência do Estado, se concedesse às autoridades um poder-dever indefinido de autotutela. Desde o famoso affaire chochet, é esta a orientação dominante no Direito francês, com os aplausos de Maurice Hauriou, que bem soube pôr em realce os perigos que adviriam para a segurança das relações sociais se houvesse possibilidade de indefinida revisão dos atos administrativos." 22

Assim, em nome da estabilidade das relações jurídicas, os atos administrativos baixados em período razoável (mínimo de 5 anos) são imutabilizados pelo tempo.

Pensar de modo contrário é trazer a baila a insegurança para a sociedade, haja vista que o Estado constantemente renova os seus governantes, que poderiam rever indefinidamente os atos passados.

O princípio sub-oculis estabiliza as relações jurídicas firmadas, convalidando os atos que no futuro sejam considerados como ilegais pela Administração.

20 MRS n. 17.444 , in RTJ 45/589

21 RMS n..$^{2} 13807$, in RTJ 37/248

22 "Revogação e Anulamento do Ato Administrativo, 1968, ed. Forense, p. 72 


\section{PRESCRIÇÃO ADMINISTRATIVA COMO UM DOS ELOS DA PRESERVAÇÃO DO ESTADO DE FATO}

Visando prestigiar a consumação do estado de fato no campo do direito administrativo, o Decreto 20.910/32, elencou o prazo de cinco anos, contados da data do fato ou ato administrativo, para que ocorra a fruição da prescrição ${ }^{23}$.

Sucede, que a prescrição elencada pelo citado comando legal não possui como finalidade apenas regular o ingresso de ações por parte dos interessados contra o poder público, funcionando também como freio a revogabilidade dos atos administrativos baixados quando o Poder Público, utilizando-se da faculdade do seu autocontrole, pretendendo revogar ou até mesmo anulá-los.

Esse raciocínio lógico depreende-se do próprio texto legal, visto que o artigo $2^{\circ}$, do Decreto 20.910/32, impõe o prazo prescricional de 5 (cinco) anos para o exercício de "todo o direito", sem exceção. O que leva o intérprete a concluir que pela diç̧ão do sadio princípio da igualdade, norma assente no caput do art. $5^{\circ} \mathrm{da}$ C.F., a consumação do lapso prescricional é endereçada tanto para o ente público, como também para o administrado.

Pensar de modo diverso seria o mesmo que desprezar o Estado Democrático de Direito, ao qual se refere a C.F. no seu artigo $1^{\circ}$.

Portanto, o ente público possui, como regra legal, a faculdade de rever os seus atos administrativos dentro de cinco anos, sob pena de, não o fazendo nesse aprazamento legal, precluir o direito de autotutela em outra oportunidade.

Ratificando o que acabamos de dizer, nada melhor do que se ater ao recente julgado do Col. STJ, que pela voz do conceituado Ministro Relator, Luiz Vicente Cernicchiaro, deixou registrado nos anais daquela Corte que a prescrição do ato administrativo afeta o direito do administrado, como, e, sobretudo, da Administração:

\footnotetext{
“Resp - ADMINISTRATIVO - PRESCRIÇÃO - A prescrição afeta o direito de o credor exigir parcelas do direito ao devedor, a decadência atinge o próprio direito. A prescrição pode ser argüida tanto pela Pública Administração, como pelo servidor. Além do princípio da igualdade, o instituto visa a resguardar, com a sequiência do tempo, a estabilidade das situações jurídicas. Conta-se tempo igual para ambos." 24
}

Nesse enredo, a prescrição administrativa estabiliza as relações intersubjetivas das partes, tornando-se irreversíveis e intocáveis.

Citado pelo eminente Ministro Cernicchiaro, o pranteado Helly Lopes Meirelles, em curtas, porém robustas, palavras, assim define a controvérsia:

23 Segundo o ex-Consultor Geral da República, Rafael Mayer, "a prescrição tem por base o interesse social pela estabilidade das relações jurídicas", in RDA 118/384

24 (STJ, Resp n² 136.204-RS/97.0041207-5, Rel. Min. Luiz Vicente Cernicchiaro, 6" T., julgado em 21/10/97). 
“A prescrição administrativa opera a preclusão da oportunidade de atuação do Poder Público sobre a matéria sujeita à sua apreciação (...). $O$ instituto da prescrição administrativa encontra justificativa na necessidade de estabilização das relações entre o administrado e a Administração e entre esta e seus servidores. Transcorrido o prazo prescricional fica a Administração, o administrado ou o servidor impedido de praticar o ato prescrito, sendo inoperante o extemporâneo." 25

Portanto, se ocorre a prescrição para a Administração revogar seus atos no prazo de 5 (cinco) anos, por igual tal preceito atinge o ato administrativo na sua essência.

Merece destaque, a jurisprudência administrativa baixada pela Consultoria Jurídica do Ministério da Justiça, em 25/3/93, que pelo Parecer CJ n² 074, da lavra da Coordenadora CEP/CJ/MJ, Dra. Rosa Maria de Guimarães Fleury, devidamente aprovado pelo ilustre Consultor Jurídico, Dr. Guilherme Magaldi Netto, ficou assim ementado:

“EMENTA: DECLARAÇÃO DE NULIDADE DE ATO ADMINISTRATIVO. PRESCRIÇÃO QÜINQÜENAL. INCIDÊNCIA. 1 - A pretensão deduzida perante a Administração Pública para rever ato com vício de nulidade está sujeita à prescrição qüinqüenal estabelecida no Decreto 20.910/32, que não pode ser relevada. 2 - "A orientação administrativa não há de estar em conflito com a jurisprudência dos Tribunais em questão de direito, mormente quando a interpretação emanada do Egrégio Supremo Tribunal Federal." (CGR, Pareceres $\mathbf{n}^{\circ}$ S-011, de 12.02,1986, 261-T, de 30.04.53; C-15, de 13.12.1960; H-76; I-222, de 11.06.73; L-211, de 04.10.1978; P-33, de 14.04.1983). 3 - Sugestão de revisão do Parecer CR/CG n ${ }^{\circledR}$ 01/92, aprovado pelo Parecer JCF-011, porque conflitante com a Jurisprudência consolidada, a doutrina predominante e o princípio da legalidade insculpido no art. 37, caput, a C.F."

E a Advocacia Geral da União, acatando a sugestão citada anteriormente pela Consultoria Jurídica do Ministério da Justiça, baixou o parecer n. ${ }^{\circ}$ CQ-10, de 6 de outubro de $1993^{26}$ :

“Ato Nulo - Revisão - Prescrição Qüinqüenal. - A prescrição qüinqüenal prevista no artigo $1^{9}$ do Decreto $\mathrm{n}^{\mathrm{9}} 20.910 / 32$ abrange tanto $o$ ato nulo, quanto o anulável. - Revisão do Parecer JCF, de 30 de novembro de 1992, da Consultoria Geral da República."

No embasamento do aludido Parecer $\mathrm{n}^{\mathrm{Q}} \mathrm{GQ}-10 / 93$, são citados alguns arestos, que, pelo brilho e eloquêencia jurídica, tornam-se necessários virem à tona, para

25 "Direito Administrativo Brasileiro", 1989, 15" ed., ed. RT, p. 577.

26 RDA 194:307-314. 
espancar qualquer tipo de dúvida quanto a prescrição do ato administrativo nulo e o anulável:

“PRESCRIÇÃO. ATO ADMINISTRATIVO. NULIDADE APONTADA POR PARTICULAR. DECURSO DO PRAZO DE CINCO ANOS. RECONHECIMENTO DA CAUSA EXTINTIVA DE ACIONAR. 1 - O Decreto $\mathrm{n}^{2} 20.910$, de $06 / 01 / 32$, ao determinar a prescrição qüinquienária de qualquer ação contra ato administrativo não fez qualquer distinção entre nulidade e anulabilidade. $O$ prazo da prescrição incide em relação a quaisquer direitos pessoais, como o são os decorrentes de relação de serviço público. 2 - A prescrição qüinqüenal referida abrange qualquer direito ou ação. 3 - Se é certo que o ato administrativo ilegítimo não se torna válido pelo tempo decorrido, qualquer que seja o período de sua duração, pois, o que é vicioso sempre continua vicioso. Certo, também, é que prescreverá, no prazo de 5 (cinco) anos a ação do interessado para invalidar, por não se justificar a instabilidade jurídica, mesmo que potencial, por todo e sempre. 4 - Em consequiência, se o interessado não agiu dentro dos cinco anos autorizados pelo ordenamento positivo, o ato, mesmo inválido, firma-se, estabiliza-se, não podendo ser mais anulado, quer por meio administrativo, quer por decisão judicial. 5 - Sentença reformada. Provimento do Recurso." 27

E Sérgio D'Andreia Ferreira ${ }^{28}$, no alto de sua cátedra, também defende o instituto da prescrição/preclusão no direito administrativo, como forma de preservar a consolidação do estado de fato:

"5. O transcurso do tempo é, sem dúvida, um dos fatos jurígenos naturais mais relevantes. Dentre seus efeitos no mundo do Direito, estão os que afetam a eficácia, outros efeitos já ocorrentes naquele mundo. Duas grandes linhas de fenômenos se identificam nessa área jurídica: de um lado, o da preclusão, decadência ou caducidade; de outro, o da prescrição. Embora muitas vezes confundidas essas duas séries de fenômenos jurídicos (o próprio Código Civil, na enumeração do art. 178, mistura-os sob o rótulo genérico da prescrição), extremam-se elas ontológica e eficacialmente. Assim, a preclusão - de que são sinônimos os termos decadência e caducidade - opera a extinção de efeitos jurídicos, isto é, de direitos, de pretensões, de ações e de exceções. Fala-se em precluir, porque o que se encontrava incluído no mundo jurídico, deixa-o de estar (Pontes de Miranda, Tratado de Direito Privado, Borsoi, Rio, $3^{\mathbf{a}}$ ed., 1970, VI/135). O que "subira" ao mundo do Direito, cai (caducidade), sendo os mesmos técnicos, embora o mais usado, o vocábulo decadência: : 'o direito cai, não decai". (fontes, ob. e loc. cits.)'

27 TRF $-5^{\circ}$ Região, Ae 195-SE, julgado em 3/8/89, in RDA 194:309.

28 "Ato Administrativo - CORREÇÃO DE OFÍCIO E PROVOCADA A ANULIBILIDADE NULIDADE - PRESCRIÇÃO", in RDP 80:69-70. 
E o STJ já teve a oportunidade de prestigiar o instituto da consumação do estado de fato, como forma de tornar irretratável o posicionamento adotado pela própria Administração:

“MANDADO DE SEGURANÇA. Ato Administrativo. Preclusão Administrativa. I - $\mathrm{O}$ ato administrativo conta com a retratabilidade que poderá ser exercida enquanto dito ato não gerar direitos a outrem, ocorrendo a existência de direitos, tais atos são atingidos pela preclusão administrativa, tornando-se irretratáveis por parte da própria Administração. II - É que, exercitando-se o poder da revisão de seus atos, a Administração tem que se ater aos limites assinalados na lei, sob pena de ferir o direito líquido e certo do particular, o que configura ilegalidade e ou abuso de poder. III — Segurança concedida." 29

Portanto, a prescrição/preclusão funcionam também como preservação do estado de fato no campo das relações com os entes públicos, desertenizando discussões de matérias que já se consolidaram no tempo.

\section{DA JURISPRUDÊNCIA SOBRE A CONSUMAÇÃO DO ESTADO DE FATO}

O STJ pacificou o entendimento de que o fato consumado é suficiente para estabilizar a relação jurídica.

A irreversibilidade do fato consumado é suficiente para imortalizar a manutenção dos efeitos do ato pelo qual a Administração se insurge como ilegal.

À guisa de ilustração, seguem os seguintes julgados do STJ:

“ADMINISTRATIVO. MANDADO DE SEGURANÇA. CURSO PROFISSIONALIZANTE. CONCLUSÃO DO ESTÁGIO. ENSINO SUPERIOR, MATRÍCULA. FATO CONSUMADO, EM DECORRENCIA DE LIMINAR CONCEDIDA. SITUAÇÃO FÁTICA JÁ CONSOLIDADA.

CIRCUNSTÂNCIAS ESPECIAIS. PROVIMENTO DO RECURSO ESPECIAL.

I - SE, NA HIPÓTESE, A ALUNA, POR FORÇA DE DECISÃO FAVORÁVEL DO JUÍZO MONOCRÁTICO, TENDO CONCLUÍDO O ESTÁGIO, JÁ VEM HÁ MUITO TEMPO FREQÜENTANDO AS AULAS DO CURSO SUPERIOR, FALTANDO APENAS DOIS SEMESTRES PARA CONCLUÍ-LO, TEM-SE CONSOLIDADA UMA SITUAÇÃO FÁTICA CUJA DESCONSTITUIÇÃO SERIA DE TODO DESACONSELHADA, SOBRETUDO SE CONSIDERADA A INEXISTÊNCIA DE PREJUÍZOS A TERCEIROS.

II - NÃO COMO REGRA GERAL, MAS EM CIRCUNSTÂNCIA E EM RESPEITO A SEGURANÇA DAS RELAÇÕES JURÍDICAS, A JURISPRU- 
DÊNCIA PREDOMINANTE DESTA EGRÉGIA CORTE, EM CASOS SEMELHANTES, TEM ADMITIDO PRESERVAR A SITUAÇÃO JÁ CONSOLIDADA E IRREVERSÍVEL, SEM QUE DELA RESULTE PREJUÍZO A TERCEIROS.

III - RECURSO PROVIDO. DECISÃO UNÂNIME."

(REsp n 34548-RS, Rel. Min. Demócrito Reinaldo, $1^{\text {a }}$ T., STJ, DOU 28/06/93, p. 12.868)

“TRANSFERÊNCIA - ALUNO. UNIVERSIDADE - SITUAÇÃO CONSOLIDADA PELO TRANSCURSO DO TEMPO, DEVE SER CONCEDIDA A SEGURANÇA.

EMBARGOS ACOLHIDOS."

(STJ, Rel. Min. Garcia Vieira, $1^{\mathbf{a}}$ T., Embargos de Declaração no REsp $n^{\mathrm{Q}}$ 139867-CE, DOU 4/5/98, p. 88)

“ADMINISTRATIVO. ENSINO SUPERIOR. EXAME VESTIBULAR. MATRÍCULA. CERTIFICADO DE CONCLUSÃO DO SEGUNDO GRAU. FATO CONSUMADO POR FORÇA DA CONCESSÃO DE LIMINAR. SITUAÇÃO CONSOLIDADA. - SE A MATRÍCULA NA FACULDADE DE ADMINISTRAÇÃO, APÓS EXAME VESTIBULAR PRESTADO HÁ MAIS DE QUATRO ANOS, FOI ASSEGURADA EM CUMPRIMENTO À DECISÃO JUDICIAL, TORNANDO O FATO CONSUMADO PELO DECURSO DO TEMPO, SEM PREJUÍZO DE TERCEIROS, MERECE RESPEITO A SITUAÇÃO JÁ CONSOLIDADA.

- PRECEDENTE JURISPRUDENCIAIS.

- RECURSO PROVIDO."

(STJ, REsp 19775-GO, Rel. Min. Hélio Mosimann, $2^{\text {a }}$ T., DOU e 28/9/92, p. 15.412)

“ADMINISTRATIVO. ALUNO MATRICULADO EM REGIME ESPECIAL E EQUIPARAÇÃO AO ALUNO REGULAR, POR DECISÃO JUDICIAL. FATO CONSUMADO. O ALUNO MATRICULADO EM REGIME ESPECIAL E EQUIPARADO, SUBSEQÜENTEMENTE, POR DECISÃO JUDICIAL, AO ALUNO REGULAR, APÓS O CUMPRIMENTO DO CURRÍCULO TEM, EM SEU FAVOR, SITUAÇÃO JURÍDICA INDISCUTIVELMENTE IRREVERSÍVEL. MERECEM PROTEÇÃO AS SITUAÇÕES CONCRETIZADAS ATRAVÉS DO TEMPO E REFERENDADAS ATRAVÉS DE DECISÕES JUDICIAIS, EM REITERADAS CONCESSÕES DE SEGURANÇA.

RECURSO CONHECIDO, POR MAIORIA E PROVIDO, POR UNANIMIDADE"

(STJ, REsp nª 49773-RS, Rel. Min. Demócrito Reinaldo, $1^{\text {a }}$ T., DOU e 17/10/94, p. 27.868)

O fato consumado, como visto, possui eco no judiciário, ficando o poder público sujeito ao limite temporal para a desconstituição dos seus atos que já produziram efeitos. 
Exemplo disto, foi o caso de um juiz de direito que ao se aposentar requereu a sua reversão, sendo deferido seu pleito perante o Poder Judiciário.

Após vários anos de prestação de serviço como Juiz revertido à ativa, o interessado requereu a sua aposentadoria, tendo o Tribunal de Contas do Estado do Rio de Janeiro se recusado em registrar o ato anterior da sua reversão, apesar de o fato administrativo se encontrar totalmente consumado.

Contra este posicionamento o Órgão Especial do Tribunal de Justiça - RJ no Ms $n^{9} 586 / 96$, prestigiou a consumação do estado de fato e concedeu a segurança, ficando assim o ementado aresto:

"Tribunal de Contas. Possibilidade de revisão de seus atos pelo Poder Judiciário (CF, XXXV). Competência constitucional das Cortes de Contas. Não a compreende o exame de melhorias funcionais posteriores aos registros iniciais e dos atos de provimentos derivados. Aposentadoria de magistrado. Anulação do respectivo ato pelo Tribunal de Contas, por recusa de registro de ato anterior de sua reversão, que não lhe foi submetido para exame. Exorbitância do Órgão Fiscalizador, com invasão da própria competência do Poder Judiciário, ao pretender desconstituir ato administrativo que havia gerado direito subjetivo. Mandado de segurança concedido."

(TJ-RJ, Rel. Des. Elmo Ameira, Órgão Especial, MS ne 586/96, por maioria, julgado em 1/9/97)

Este julgado, em conjunto com os demais, prestigiam a estabilidade da fruição do tempo, com a convalidação ou sanatória de atos que possuam no seu nascimento equívocos ou sejam considerados ilegais.

Pela própria lei da natureza existe um prazo hábil para a revisão de atos praticados. O instituto da prescrição foi criado como forma de possibilitar a sociedade certa estabilidade nas relações das pessoas entre elas ou delas com o poder público. Não existindo prerrogativa do ente de direito público, que em nome do próprio interesse público é obrigado em respeitar a estabilidade das suas relações com terceiros.

A eternização da determinada situação de fato é suficiente para consolidá-la no mundo jurídico.

Subsistindo, assim, o interesse público como fator imperioso na manutenção da estabilidade da relação com o Estado.

\section{CONCLUSÃO}

A indeterminação e a perpetuidade da Administração Pública rever seus atos ad eternum, criaria verdadeiro caos para a sociedade, administrados e servidores públicos, em razão da criação da instabilidade jurídica que seria vivida por todos.

Sendo certo, que não se pode esquecer as sempre sóbrias colocações do magistral Caio Tácito ${ }^{30}$ : 
“também o direito público valoriza o decurso do tempus como elemento tanto aquisitivo como extintivo de direito e obrigações."

E a colocação desse gigante do direito administrativo teve eco na Suprema Corte, que fixou a matéria prescricional como operante até no terreno do direito disciplinar, estabilizando a situação fática, consoante deixou estampado o emérito Ministro Moreira Alves, no seguinte julgado ${ }^{31}$ :

“Em matéria de prescrição em nosso Sistema Jurídico, inclusive no terreno do direito disciplinar, não há que se falar em jus singulare, uma vez que a regra é a da prescritibilidade."

Assim, nessa moldura, a consumação do estado de fato funciona também em favor da coletividade, estabilizando situações jurídicas constituídas sob o manto da boa fé, e acabando com o velho dogma de que a Administração Pública pode fazer tudo o que entender ser necessário, inclusive rever seus atos já sepultados pelo decurso dos anos, sob o argumento de que, por serem nulos, não geram direitos. 